\title{
AVALIAÇÃO FORMATIVA DA APRENDIZAGEM: A EXPERIENNCIA DO CONSELHO DE CLASSE
}

RUBIA CAVALCANTE VICENTE MAGNATA ANA LÚCIA FELIX DOS SANTOS

\section{RESUMO}

O estudo teve por objeto o conselho de classe como instrumento da avaliação formativa da aprendizagem. Buscou identificar as concepções de avaliação da aprendizagem que perpassam a experiência do conselho de classe no Colégio de Aplicação da Universidade Federal de Pernambuco. Toma a avaliação formativa como aquela que favorece o desenvolvimento do aluno, pois se configura num processo contínuo e permanente de acompanhamento das aprendizagens. Fundamentado no método de estudo de caso, foram feitas observações de reuniões do conselho de classe, entrevistas semiestruturadas e análise de documentos. Os resultados revelam que as concepções intrínsecas à dinâmica do funcionamento do conselho de classe apontam para compreensão e prática dentro de uma perspectiva de avaliação formativa, e que as práticas de desenvolvimento do conselho de classe revelam a possibilidade de implantação de uma avaliação construtiva e coletiva.

PALAVRAS-CHAVE AVALIAÇÃO DA APRENDIZAGEM • AVALIAÇÃO FORMATIVA • CONSELHO DE CLASSE • COLÉGIO DE APLICAÇÃO - UFPE. 


\section{RESUMEN}

El estudio tuvo como objeto el consejo de clase como instrumento de la evaluación formativa del aprendizaje. Trató de identificar las concepciones de evaluación del aprendizaje que se encuentran presentes en la experiencia del consejo de clase en el Colégio de Aplicação de la Universidad Federal de Pernambuco. Toma la evaluación formativa como aquella que favorece el desarrollo del alumno, ya que se configura en un proceso continuado y permanente de seguimiento de los aprendizajes. Fundamentado en el método de estudio de caso, se efectuaron observaciones de reuniones del consejo de clase, entrevistas semiestructuradas y análisis de documentos. Los resultados revelan que las concepciones intrínsecas a la dinámica del funcionamiento del consejo de clase señalan comprensión y práctica dentro de una perspectiva de evaluación formativa, y que las prácticas de desarrollo del consejo de clase revelan la posibilidad de implantación de una evaluación constructiva y colectiva.

\section{palabras clave eVAluación del aprendizaje • EVALUACIÓN FORMATIVA • CONSEJO DE CLASE • COLEGIO DE APLICACIÓN - UFPE.}

\section{ABSTRACT}

This study aimed to evaluate the class council as a tool for the formative assessment of learning. Its intent was to identify the concepts of learning assessment that pervade the experience of class councils in the Colégio de Aplicação of the Federal University of Pernambuco. Formative assessment promotes the development of students, as it is built in a continuous and permanent process for monitoring learning. Observations of class council meetings, semi-structured interviews and document analysis were carried out based on case study methodology. The results show that the conceptions which are intrinsic to the dynamic functioning of class councils point to the understanding and practice from the perspective of formative assessment, and that the practices of class council development indicate the possibility of implementing a constructive and collective form of assessment.

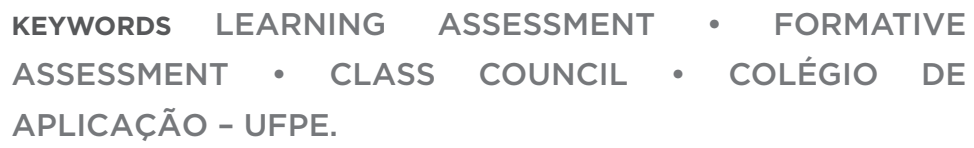




\section{INTRODUÇÃO}

A investigação reflete sobre o conselho de classe como instrumento da avaliação da aprendizagem numa perspectiva formativa. A partir da consideração de que ele pode se constituir como espaço coletivo de reflexão, de construção e de reformulação das práticas pedagógicas a fim de favorecer o desenvolvimento do processo ensino-aprendizagem, buscamos analisar como essa instância é compreendida por professores e de que forma contribui para a avaliação da aprendizagem dos alunos.

Consideramos a necessidade de melhor compreender a estruturação e o funcionamento do conselho de classe, a partir de sua especificidade como espaço coletivo de avaliação das aprendizagens de discentes. A lógica de um espaço coletivo de avaliação da aprendizagem remete ao entendimento de que o professor não deveria sozinho determinar o futuro do aluno, assim, é prudente agregar diferentes olhares, percepções, entendimentos e práticas avaliativas em função do mesmo objetivo educacional: o desenvolvimento e a melhoria da aprendizagem do aluno. 
O conselho de classe colabora para a discussão e reflexão conjunta das práticas pedagógicas, estabelece o diálogo entre professores, orientadores, alunos e gestão por meio de uma avaliação que ressalta o conhecimento construído e que permite a reformulação de estratégias a fim de favorecer o desenvolvimento da aprendizagem. Mesmo que algumas pesquisas venham evidenciando a existência de buscas pela materialização desse formato de conselho (GUERRA, 2006; PEREIRA, 2004), outras tantas apontam ainda para o fato de que escolas e redes de ensino têm utilizado o conselho de classe como instrumento de certificação e seleção. Ele funciona com a perspectiva de promover ou reter o estudante diante de um padrão estabelecido, seja pela própria instituição, seja pelo professor, ratificando, muitas vezes, o fracasso escolar dos alunos (MATTOS, 2005; GUERRA, 2006).

Geralmente essas reuniões não assumem a função formativa da avaliação, mas se apoiam na função somativa da avaliação, especificamente nas subfunções de seleção e certificação. Varjal (2007, p. 10) nos alerta que a subfunção de seleção da avaliação não é, de fato, adequada ao ambiente escolar:

[...] só tem serventia em contextos de disputa ou de concorrência quando as aprendizagens dos candidatos são avaliadas para fins de provisão de vagas ou para concessão de credenciamentos para execução de obras pública.

Essa face somativa da avaliação da aprendizagem, a qual geralmente se vincula à prática do conselho de classe, está relacionada ao que Luckesi $(2006$, p. 17) denomina de "pedagogia do exame”. Ao observar a prática da avaliação da aprendizagem nas escolas do Brasil, esse autor destaca que esta ganhou um espaço tão grande na prática educativa escolar que a prática pedagógica passou a ser direcionada por exames e provas. Assim, por um lado, os alunos concentram sua atenção na promoção pelas notas, por outro, os professores fazem uso das provas como instrumento de controle, de hierarquização e de classificação. E, dessa maneira, ao centrar a atenção nos exames, a avaliação da aprendizagem 
deixa de cumprir a sua função de "subsidiar a decisão da melhoria da aprendizagem” (LUCKESI, 2006, p. 25).

Os alunos, desse modo, são comparados e classificados em virtude de um padrão que gera estigma e exclusão. Libâneo (1994, p. 41) colabora com nossa reflexão:

Muitas vezes, inadvertidamente, os professores estabele-
cem padrões, níveis de desempenho escolar, tendo como
referência o aluno considerado "normal" - estudantes com
melhores condições socioeconômicas e intelectuais vis-
tos como modelos de aluno estudioso. Crianças que não
se enquadram nesse modelo são consideradas carentes,
atrasadas, preguiçosas, candidatando-as à lista que o pro-
fessor faz dos prováveis reprovados.

Como se pode ver, a avaliação da aprendizagem ainda está atrelada a funções de controle, classificação, seletividade e hierarquia. Compreendemos que a problemática se concentra no desvio da atenção à especificidade do educando, sendo exigidos saberes e competências, mas não lhe são oferecidos os caminhos para buscar melhorias no seu processo de aprendizagem.

Nesse contexto, em que se insere a avaliação da aprendizagem no interior das práticas pedagógicas, levantamos questões relacionadas diretamente ao conselho de classe: como ele vem sendo usado na perspectiva da avaliação? Quais as possibilidades de sua utilização numa perspectiva de avaliação formativa?

Tais questões orientaram esta pesquisa. Tomando o conselho de classe do Colégio de Aplicação da Universidade Federal de Pernambuco (CAp-UFPE) especificamente, nos propomos a caracterizar sua estrutura e funcionamento; investigar como ele é compreendido pelos professores; analisar de que forma contribui para a avaliação formativa da aprendizagem dos alunos; e, por fim, identificar e analisar a concepção de avaliação da aprendizagem implícita na dinâmica de funcionamento de um conselho de classe.

A opção por tal campo empírico se deu pela suposição de que esse conselho pode constituir-se como exemplo de organização e funcionamento coletivo e reflexivo atuando 
em prol e no interior de um processo de ensino-aprendizagem, em que a avaliação da aprendizagem assume um papel formativo, convertendo-se em um processo de acompanhamento, análise, criação e reformulação de estratégias pedagógicas que possibilitam o desenvolvimento do educando. Tal suposição se ampara na forma e nos objetivos embasadores da experiência do conselho no CAp-UPFE, conforme explicitaremos no tópico "Avaliação e conselho de classe: analisando os dados da realidade pesquisada”.

Para responder aos nossos questionamentos e atingir o objetivo principal deste estudo, utilizamos uma abordagem metodológica qualitativa que, segundo Richardson (1999, p. 80),

Pode descrever a complexidade de determinado problema, analisar a interação de certas variáveis, compreender e classificar processos dinâmicos vividos por grupos sociais, contribuir no processo de mudança de determinado grupo e possibilitar, em maior nível de profundidade, o entendimento das particularidades do comportamento dos indivíduos.

Considerando a especificidade do campo empírico desta pesquisa, procedimentalmente optamos por um estudo de caso que consiste "no estudo profundo e exaustivo de um ou poucos objetos, de maneira que permita seu amplo e detalhado conhecimento" (GIL, 2006, p. 54). Em articulação com essa opção, selecionamos as seguintes técnicas de coleta de dados: observação dirigida, entrevista semiestruturada e análise de documentos pertinentes à instituição estudada.

Os dados foram coletados em três momentos. No primeiro, por meio dos documentos normativos ${ }^{1}$ do CAp-UFPE, a saber: o Projeto Político Pedagógico Institucionalizado/2012 (PPPI), a Instrução Normativa n. 01/93, a Instrução Normativa n. 01/99 e as Orientações Pedagógicas Iniciais do Serviço de Orientação de Experimentação Pedagógica (UNIVERSIDADE FEDERAL DE PERNAMBUCO, 2012a).

No segundo momento, fizemos observação dirigida em cinco reuniões do conselho de classe promocional ${ }^{2}$ do ano letivo de 2013, abrangendo reuniões de turmas do ensino fundamental e do ensino médio. Tais observações foram
1 Os documentos normativos foram obtidos no site do CAp (<www.ufpe. br/cap >), exceto as Orientações Pedagógicas, cuja cópia nos foi cedida por uma funcionária do Serviço de Orientação e Experimentação Pedagógica (Soep). 
registradas em um diário de campo e para utilização das observações/intervenções realizadas pelos sujeitos envolvidos no conselho adotamos no momento das análises a seguinte nomenclatura: Conselheiro-Professor 1 (CP1); Conselheiro-Professor 2 (CP2); e assim por diante.

Uma terceira estratégia utilizada foi a aplicação de entrevistas semiestruturadas, que envolviam questões sobre avaliação da aprendizagem e conselho de classe, com uma amostra de dez professores, os quais foram escolhidos a partir da representatividade de diferentes áreas do conhecimento, mas também da disponibilidade dos docentes em participar da pesquisa. Conseguimos reunir nesse grupo professores de diferentes disciplinas: Educação Artística (1), Português (1), Francês (1), Educação Física (1), Matemática (2), História (1), Geografia (1), Sociologia (1) e Física (1), dessa forma, o objetivo foi apreender diferentes concepções de avaliação considerando o referencial de formação e de experiência de cada docente entrevistado. Para utilização dos trechos de falas dos professores entrevistados no momento das análises, adotamos a seguinte nomenclatura: Professor 1 (P1), Professor 2 (P2), e assim por diante.

Para avaliar os dados, optamos pela análise de conteúdo temática. Minayo (2010, p. 209) afirma que "fazer uma análise temática consiste em descobrir os núcleos de sentido que compõem uma comunicação cuja presença ou frequência signifiquem alguma coisa para o objetivo analítico visado”. Assim, durante a fase de exploração do material, buscamos encontrar categorias relacionadas à especificação dos temas, assim como privilegiar a dimensão qualitativa dos temas presentes nos textos analisados.

\section{AVALIAÇÃO DA APRENDIZAGEM E O PROCESSO EDUCATIVO}

Como sabemos, o campo conceitual da avaliação educacional e da avaliação da aprendizagem passou e ainda passa por processos frequentes de redefinição e reafirmação, a ponto de autores como Guba e Lincoln $\left(1989^{3}\right.$ apud FERNANDES, 2005) defenderem a existência de diferentes gerações de 
avaliação da aprendizagem escolar. Tais gerações são marcadas pela definição dos objetivos e objetos da avaliação da aprendizagem escolar e estão marcadas, em um extremo, pela concepção de avaliação como medida, e, no outro, por uma concepção de avaliação como negociação. Importa destacar que a ação do aluno e a do professor no processo de ensinar e aprender estão sempre sendo postas em xeque por diferentes correntes que debatem e defendem a avaliação da aprendizagem escolar.

É certo afirmar que Michael Scriven (1967) teve um papel fundamental na definição da avaliação quando ressaltou que esta exerce diferentes papéis, mas possui apenas um objetivo: determinar o mérito ou o valor do que se avalia. Para esse autor, os papéis se expressam nas formas como os resultados das avaliações são utilizados. Tal assertiva pode não ser aceita por muitos teóricos, mas trouxe uma direção para os processos de avaliar e colocou por terra a ideia da neutralidade do avaliador, pois emitir julgamentos tem sempre uma carga de subjetividade.

Aqui cabe destacar que avaliar a aprendizagem dos alunos guarda a necessidade de interpretação de dados que serão valorados. Nesse caso, o avaliador deve construir uma habilidade fundamental: a de saber julgar.

Julga-se o mérito ou o valor das aprendizagens. O juízo de mérito incide sobre os atributos do conhecimento, do procedimento ou da atitude cuja aprendizagem constitui o objeto da avaliação. [...] Já o juízo de valor, sendo relativo, incide sobre o mérito adequado às possibilidades desse sujeito. Sua missão considera necessariamente o contexto em que se situa o sujeito da avaliação. Dessa forma, o juízo de valor inclui necessariamente um juízo de mérito. Não se pode julgar o valor de algo sem uma apreciação de seu mérito, no entanto, o julgamento de valor vai mais além porque adequa ou relativiza o rigor do mérito de acordo com o contexto do sujeito. (VARJAL, 2007, p. 4)

Simões (2000) também nos lembra que Scriven vai apontar duas funções para a avaliação: a função somativa, relacionada a avaliar ao final do processo a fim de fundamentar 
uma tomada de decisão, e a função formativa, que corresponde a avaliar durante o processo, obtendo informações para regular e melhorar o que está sendo avaliado.

Essa perspectiva de avaliação formativa está apoiada numa concepção de avaliação como negociação e construção proposta por Guba e Lincoln (1989 apud FERNANDES, 2005), a qual possui postura construtivista, estando fundamentada, em grande parte, num conjunto de princípios entre os quais se destacam:

Os professores devem partilhar o poder de avaliar com os alunos e outros intervenientes e devem utilizar uma variedade de estratégias, técnicas e instrumentos de avaliação; b) a avaliação formativa deve ser a modalidade privilegiada de avaliação, com a função principal de melhorar e de regular as aprendizagens; c) o feedback, nas suas mais variadas formas, frequências e distribuições, é um processo indispensável para que a avaliação se integre plenamente no processo do ensino-aprendizagem [...]. (FERNANDES, 2005, p. 62)

Destacamos, então, que no decorrer do tempo e dos contextos históricos e sociais a avaliação sofreu significativa evolução, deixando de considerar o aluno como único objeto, passando a avaliar os programas, o currículo, as escolas e os professores, movimento considerado bastante relevante, pois passou a entender a avaliação como um elemento da prática pedagógica capaz de subsidiar a melhoria da educação.

O movimento acima destacado, a partir da contribuição de Scriven e de outros teóricos, lança no campo educativo a questão da avaliação formativa que se caracteriza

[...] por um processo de interpretação-intervenção sobre o desenvolvimento do ensino-aprendizagem com a finalidade de garanti-lo, de aprimorá-lo, redirecioná-lo, enfim, de dar condições efetivas para que o ensino e a aprendizagem ocorram com sucesso. (LUIS, 2010, p. 41)

De forma geral, podemos dizer que esse campo avaliativo se opõe ao processo que reduzia a avaliação à simples medida ou descrição das aprendizagens dos alunos. Mas, 
também, não se limita apenas a realizar julgamento sobre o mérito ou o valor de tais aprendizagens. E mesmo que a expressão "avaliação formativa" não seja um consenso entre os estudiosos da área, muitos defendem uma perspectiva crítica de abordagem, fugindo de concepções classificatórias, seletivas, excludentes e discriminatórias, e indo ao encontro de uma avaliação que busca diagnosticar as dificuldades apresentadas pelos alunos de forma que os professores possam, no decorrer do processo ensino-aprendizagem, avaliar suas práticas e reestabelecer critérios e estratégias de promoção do desenvolvimento do aluno.

Nesse sentido, a avaliação não se constitui apenas como análise de resultados, mas como processo, que no início consiste em conhecer o que o aluno "sabe, sabe fazer e é, e o que pode chegar a saber, saber fazer ou ser, e como aprendê-lo", denominada de avaliação inicial (ZABALA, 1998, p. 199). O passo seguinte corresponde à avaliação reguladora que é "o conhecimento de como cada aluno aprende ao longo do processo de ensino/aprendizagem, para adaptar às novas necessidades que se colocam". Em seguida, a avaliação final que corresponde "aos resultados obtidos e aos conhecimentos adquiridos" (ZABALA, 1998, p. 200) e a avaliação somativa ou integradora entendida como

Um informe global do processo que, a partir do conhecimento inicial (avaliação inicial); manifesta a trajetória seguida pelo aluno, as medidas específicas que foram tomadas, o resultado final de todo o processo e, especialmente a partir deste conhecimento, as previsões sobre o que é necessário fazer de novo. (ZABALA, 1998, p. 201)

Outros autores também vão nos ajudar a abandonar as práticas avaliativas meramente classificatórias. Luckesi (2006, p. 81) propõe a avaliação diagnóstica, a qual deve ser assumida como

[...] instrumento de compreensão do estágio de aprendizagem que se encontra o aluno, tendo em vista tomar decisões suficientes e satisfatórias para que se possa avançar no seu processo de aprendizagem. 
Hoffmann (2009, p. 16) também colabora com nossa reflexão quando afirma que

[...] as práticas avaliativas classificatórias fundam-se na competição e no individualismo, no poder, na arbitrariedade presentes nas relações que se estabelecem entre professores e alunos, entre os alunos e entre os próprios professores,

destacando a importância da avaliação mediadora como um processo de

[...] permanente troca de mensagens e de significados, um processo interativo, dialógico, espaço de encontro e de confronto de ideias entre educador e educando em busca de patamares qualitativamente superiores de saber. (HOFFMANN, 2009, p. 77)

A materialização do processo avaliativo em sala de aula vai acontecer a partir da utilização e de uma abordagem metodológica que se agrega aos princípios acima discutidos. $\mathrm{O}$ professor deve lançar mão de diferentes instrumentos avaliativos, desde os mais tradicionais aos mais alternativos. Uma avaliação formativa insiste na utilização de uma diversidade de instrumentos para ajudar o professor a coletar dados sobre as aprendizagens dos seus alunos. Tradicionalmente, conhecemos os instrumentos de avaliação mais presentes em nossa prática em sala de aula: as provas escritas, as provas orais, os seminários, os trabalhos em grupo, entre outros. Aqui discutiremos com mais profundidade a utilização de um instrumento que tem um caráter mais coletivo, e entendemos que a ele pode ser agregado um caráter formativo: o conselho de classe.

\section{O CONSELHO DE CLASSE COMO INSTRUMENTO DE AVALIAÇÃO DA APRENDIZAGEM ESCOLAR}

Como "meios e modos de tornar a avaliação mais justa, mais digna e humana”, Sant'Anna (2010, p. 7) apresenta-nos alguns instrumentos, entre eles: o conselho de classe como

[...] a atividade que reúne um grupo de professores da mesma série, visando em conjunto chegar a um conhecimento 
mais sistemático da turma, bem como acompanhar e avaliar cada aluno individualmente, através de reuniões periódicas. (SANT'ANNA, 2010, p. 87)

Sua utilização é importante porque

[...] 1) favorece a integração entre os professores, aluno e família; 2) torna a avaliação mais dinâmica e compreensiva; 3) possibilita um desenvolvimento progressivo da tarefa educacional; 4) conscientiza o aluno de sua atuação; 5) considera as áreas afetiva, cognitiva e psicomotora; 6) a comunicação dos resultados é sigilosa e realizada pelo professor conseIheiro, eleito pela turma; 7) os professores mais radicais, que tentam apresentar seus conceitos predeterminados, são ajudados pelos colegas a visualizarem o aluno como um todo e a terem uma concepção clara dos propósitos de uma avaliação formativa. (SANT'ANNA, 2010, p. 93)

Considerar o conselho de classe como um instrumento de avaliação formativa é compreendê-lo como instância de fundamental importância na escola e pensá-lo a partir de múltiplas características. Por exemplo: reúne diferentes óticas e posicionamentos num espaço de encontro; objetiva avaliar o desempenho do aluno desenvolvendo reflexões conjuntas sobre as práticas pedagógicas existentes; ajuda a criar novos encaminhamentos que possibilitem melhores apropriações de conhecimentos; entre outros. Isso porque ao processo de avaliação da aprendizagem, geralmente dirigido e determinado pela figura solitária do professor, somam-se elementos de coletividade, o que pode contribuir sobremaneira com decisões qualitativas em relação ao destino acadêmico dos alunos.

No Brasil, o conselho de classe está regulamentado pela Lei de Diretrizes e Bases (LDB) n. 9.394/96, art. 14, II, que destaca a importância da "participação da comunidade escolar e local em conselhos escolares ou equivalentes”. Embora ela não explicite claramente o conselho de classe, ele é entendido como inserido na dinâmica da escola por se tratar de um órgão que requer a contribuição conjunta dos atores do processo ensino-aprendizagem. 
E ainda que a LDB n. 9.394/96 não trate de forma explícita a avaliação da aprendizagem numa perspectiva formativa, ela dá indícios de que o formato de verificação do rendimento escolar deve ser realizado com características correspondentes a essa função da avaliação, entre os quais se destaca:

[...] avaliação contínua e cumulativa do desempenho do aluno, com prevalência dos aspectos qualitativos sobre os quantitativos e dos resultados ao longo do período sobre os de eventuais provas finais. (BRASIL, 1996, art. 24, V, a)

Dessa forma, torna-se possível pensar na relação entre o conselho de classe e a avaliação formativa da aprendizagem, pois esse espaço de avaliação, além de reunir diferentes percepções avaliativas, também define estratégias pedagógicas em conjunto no decorrer de um processo constante, contínuo. Contínuo porque o desenvolvimento humano ocorre ao longo da vida, o ser humano não é um ser acabado, pronto, é um ser em transformação. Pois, como nos diz Freire (2002, p. 73), é "na inconclusão humana que a educação se torna um 'quefazer' permanente”.

Sendo assim, não se pode pensar no conselho de classe como momentos estanques, como paradas, mas como o movimento de análise e crítica sobre o que se vem fazendo para melhorar a prática educativa.

Hoffmann (2000) indica o surgimento de alternativas para escapar do perigo desse conselho se resumir à apresentação de resultados e reclamações sobre os alunos, como a participação dos alunos, dos pais, a implantação de pré-conselhos e outros, com o objetivo de aprofundar o diálogo entre os sujeitos da avaliação e maior consciência dos processos vivenciados.

Nesse sentido, é importante refletir sobre o conselho de classe como um encontro formal e sistematizado, mas, profundamente reflexivo, colaborativo e responsável, de professores de diferentes disciplinas, com os diferentes profissionais de orientação pedagógica e educacional para buscarem juntos entendimentos sobre o porquê, como fazer e o que se quer de uma avaliação comprometida com a formação humana.

No entanto, é importante trazer para o debate posições distintas sobre essa instância avaliativa. Mattos (2005) 
revelou que os conselhos de classe, nas escolas observadas no Rio de Janeiro, são praticamente a única instância coletiva existente no interior dos processos pedagógicos das escolas.

Assim, à função precípua de avaliação do processo de aprendizagem, os conselhos de classe são vistos, em algumas escolas, como podendo proporcionar uma discussão livre entre colegas, com a finalidade de buscar soluções para os problemas diagnosticados. (MATTOS, 2005, p. 217)

No entanto, essa autora também vai afirmar que é no interior dessas instâncias avaliativas que

[...] as professoras se sentem mais livres para manifestar suas impressões sobre seus alunos e alunas. Tais reuniões permitem, assim, reforçar aspectos individuais da prática docente, através do apoio de seus pares. (MATTOS, 2005, p. 217)

Tal afirmação nos traz uma preocupação sobre a questão da coletividade e da individualidade da ação avaliativa, pois o conselho de classe pode se transformar apenas em uma instância na qual os professores vão reafirmar sua decisão e seus julgamentos sobre determinados alunos. Essa pesquisa observou os conselhos com uma dinâmica implicada, muitas vezes, em relatar o fracasso escolar dos alunos, explicar esse fracasso a partir de elementos extraescolares e apontar soluções extraclasse (há indicações implícitas para encaminhamento dos alunos para psicólogos, fonoaudiólogos, psicopedagogas, etc.).

Já a pesquisa de Pereira $(2004$, p. 2$)$ apresenta relatos de uma "cultura de faz de conta" no interior da dinâmica dos conselhos de classe, ou seja, um conselho pode servir apenas "para o cumprimento do calendário escolar" e caracteriza-se como "uma tarefa rotineira, aborrecedora, ineficiente e sem função avaliativa”. A partir das observações elaboradas durante a pesquisa, o autor nomeia os conselhos de classe a partir de determinadas características.

○ "Conselho Bingo" onde "os nomes são gritados para um grupo de professores que vão utilizando significantes do tipo 'passa'; 'este foi', 'este tá bom'; 'esquece, 'Ih, parou...'; 
'corre com isso, você sabe que não adianta..." [...] Outro tipo de Conselho de Classe que emerge de nossas observações é ao que chamamos de "Conselho UTI ou Necrotério". Os coordenadores e professores estão reunidos em uma sala, vão ditando os nomes, às vezes o número da chamada, e, aos poucos, se escutam frases do tipo: "tá morto"; "este aí já morreu"; "é só enterrar"; "tá mal, mais um pouquinho e foi"; "não adianta mais, nem com reza brava"; "sem chance"; "tá muito fraquinho... é melhor fazer um reforço... quem sabe repetir para ficar mais forte". Um terceiro tipo de Conselho de Classe observado é o "Plangente". Um espaço aberto para todo o tipo de lamentações: "não tenho tesão, esta é a pior turma"; "esta é a turma dos alunos-problema"; "essa aí só sabe conversar"; "um bando de chatinhos"; "nós não prestamos para mais nada, por isso somos professores". (PEREIRA, 2004, p. 2-3)

Tais pesquisas e resultados revelam o conselho de classe como um campo controverso e por vezes inoperante. No entanto, a experiência encontrada no Colégio de Aplicação da UFPE pode nos dar elementos para confirmar a possibilidade de um conselho com características avaliativas aproximadas de uma perspectiva coletiva e formativa. É isso que tentamos buscar com nossa pesquisa.

\section{AVALIAÇÃO E CONSELHO DE CLASSE: ANALISANDO OS DADOS DA REALIDADE PESQUISADA}

Nesta seção apresentaremos nossos achados durante a coleta de dados. No primeiro momento apresentaremos o perfil do CAp-UFPE, depois apontaremos as características de funcionamento do conselho de classe determinado pelos documentos normativos. Por fim, discutiremos as concepções de avaliação que foram reveladas nas observações e entrevistas com os professores.

\section{A) SITUANDO O CAMPO DE ESTUDO}

O CAp-UFPE foi fundado em 10 de março de 1958 com o nome de Ginásio de Aplicação, sediado no bairro da Boa Vista, integrado à Faculdade de Filosofia de Pernambuco, 
funcionando como laboratório de estudos e aplicação das teorias pedagógicas. Em 1962, por meio do Parecer n. 292 do Conselho Federal de Educação, foi transformado em um espaço de experimentação e demonstração de inovações pedagógicas para atender às disciplinas de Prática de Ensino. Com a implantação do ensino de $2^{\circ}$ grau ampliando os níveis de ensino, em 1969 passou a ser denominado Colégio de Aplicação. Por determinação do Conselho Universitário, o Colégio foi transferido para o campus universitário no bairro da Cidade Universitária na cidade do Recife em 1976, onde funciona até a presente data, vinculado ao Centro de Educação da UFPE (UNIVERSIDADE FEDERAL DE PERNAMBUCO, 2012b).

Atualmente, o CAp funciona com jornada ampliada, oferecendo duas turmas de cada ano, do $6^{\circ}$ ao $9^{\circ}$ do ensino fundamental, e duas turmas de cada ano, do $1^{\circ}$ ao $3^{\circ}$ do ensino médio. O corpo discente é composto por 414 alunos e o corpo docente por 42 professores efetivos e dez professores substitutos, sendo a grande maioria mestres e doutores. ${ }^{4}$

O Colégio de Aplicação na sua dinâmica diária, além do ensino, tem como princípio norteador o oferecimento de atividades em programas de pesquisa e de extensão.

\section{B) A FACE FORMATIVA DO CONSELHO DE CLASSE DO} CAP-UFPE: REFLEXÕES A PARTIR DOS DOCUMENTOS Formalmente, o funcionamento do conselho de classe está instituído e registrado na Instrução Normativa n. 01/93, art. 2, III, pelo qual assume a função de órgão técnico do Colégio, tendo como competências:

a. analisar os objetivos da série, das disciplinas e das práticas e de suas etapas, bem como os procedimentos a serem adotados para a sua obtenção;

b. avaliar a aprendizagem dos alunos nos seus diferentes aspectos;

c. deliberar quanto à aprovação ou não dos alunos, de conformidade com as normas regulamentares e com as normas complementares estabelecidas pelo C.T.A. (Conselho Técnico Administrativo);

d. diagnosticar as causas da deficiência de aprendizagens dos alunos; 
e. solicitar, quando necessário, colaboração de especialista do Colégio ou externo, para orientar o seu trabaIho de diagnóstico;

f. sugerir linhas de ação a serem tomadas pelos professores para com a classe;

g. elaborar, para apreciação pelos órgãos competentes, propostas de alteração dos objetivos e conteúdo curricular da série;

h. realizar outras tarefas próprias de sua natureza que Ihe sejam atribuídas pelo coordenador geral.

Como se pode ver, essa instância de avaliação colegiada assume diferentes funções, inclusive a de analisar os objetivos das séries e das diferentes disciplinas. Tal função está ancorada numa perspectiva que busca vincular avaliação com objetivos de aprendizagem em diversas instâncias. Quando se refere a avaliar as aprendizagens em seus diferentes aspectos, o documento amplia as funções avaliativas, mas também não delimita claramente os tais "diferentes aspectos". Tais aspectos podem ser apreendidos na continuidade dos itens, que se referem a diagnósticos e sugestões de linhas de ação com vistas a tomadas de decisão sobre o processo. Por outra parte, fica claro que a função somativa, numa perspectiva certificativa e seletiva, também é elemento constitutivo do conselho de classe e acontece na última reunião do ano letivo (conselho promocional). Ou seja, há também a intencionalidade de decidir a progressão ou não do aluno e isso nos revela uma contradição com a proposta de avaliação formativa.

A Instrução n. 01/99, que fixa normas e orienta procedimentos para a avaliação da aprendizagem dos alunos, apresenta o conselho de classe como

[...] instância privilegiada de reflexão sobre a prática pedagógica, é responsável pela tomada de decisão sobre promoção de alunos, intermediando a relação entre os sujeitos avaliados.

A forma como o conselho de classe do CAp-UFPE se organiza revela sua face formativa, dado que atua durante todo o 
período letivo. Ele está organizado em reuniões bimestrais, dispostas da seguinte forma: a) uma reunião no início do ano letivo para prognóstico das situações de aprendizagem vivenciadas no ano anterior; $b$ ) três reuniões para acompanhamento pedagógico; c) e uma última para efeito promocional dos alunos, ou seja, na qual são analisadas e divulgadas as aprovações e retenções dos alunos. Durante a semana em que se realizam os conselhos de classe, exceto o de prognóstico, a escola fica com as aulas suspensas, procedimento já previsto no calendário acadêmico, respeitando-se os 200 dias letivos.

Nesse sentido, pode-se observar que a própria dinâmica do conselho de classe desse Colégio revela uma orientação para a avaliação formativa quando propõe uma primeira reunião para diagnóstico inicial, na qual os professores discutem sobre as dificuldades e quais as melhores estratégias pedagógicas para trabalhar com a turma, e também apresentam o planejamento para a sua disciplina.

As três reuniões seguintes são caracterizadas pelo acompanhamento das aprendizagens que dão direcionamento evolutivo ao processo de ensino e aprendizagem. Espera-se que professores e alunos se tornem participantes ativos na avaliação, refletindo sobre o que se alcançou e o que ainda falta realizar. Segundo os documentos e os depoimentos dos professores, tais reuniões são marcadas por momentos de discussão e reflexão, autoavaliação e avaliação mútua, como explicita essa fala:

De certa forma, o conselho é como se fosse um mediador, um mobilizador das práticas de avaliação. Então, nesse conselho, a minha prática de certa forma quando eu falo interfere na do outro, quando ele também fala da prática dele, então essas relações, essas trocas, ajudam a ter a concepção de avaliação do conselho que seria a mediação de todas essas e isso geraria uma prática de avaliação do próprio conselho de sempre pensar o processo, de se pensar o processo de ensino-aprendizagem. Nós tivemos já situações assim que os alunos chegaram e colocaram: "- Nós queremos mudar o professor, não queremos mais esse professor". Então no conselho, o professor lá, balizava, falava, conseguiase até chegar a conciliação, assim, o aluno pode perceber que ele também tinha determinadas falhas que eram necessárias de 
serem revistas e refeitas, e o professor também. Então eu acho que nós já tivemos momentos que a prática de avaliação do conselho e a concepção desse conselho como sempre um coletivo, ajudou a mudar, a mudar situações de sala de aula. (P2)

A última reunião, caracterizada para fins promocionais, realiza-se para verificar os resultados do processo avaliativo durante o ano letivo, e são discutidos nesse momento o que se fez, o que se alcançou e qual decisão tomar a partir desse balanço.

Participam das reuniões do conselho de classe: os professores das disciplinas de cada turma, os representantes dos Serviços de Orientação Educacional (SOE) e o Serviço de Orientação e Experimentação Pedagógica (Soep), estagiários e alunos (estes últimos participam apenas das três reuniões de acompanhamento). Cada reunião é coordenada por um supervisor de classe, que é

[...] um professor que leciona na turma e que está aten-

to à formação dos alunos ao longo do ano, buscando acompanhar o seu desenvolvimento e formação, para além da disciplina que leciona. (UNIVERSIDADE FEDERAL DE PERNAMBUCO, 2012a, p. 3)

Aqui também encontramos limites para a perspectiva de avaliação formativa, pois na última e, pode-se dizer, mais importante reunião do conselho, não há participação de alunos, sendo este um bom elemento de debate, mas que não conseguimos aprofundar nesta pesquisa. Mesmo assim, é possível supor que relações de poder entre professor e aluno estão em jogo e colocam limites para um processo de avaliação mais horizontal. Ainda há caminhos e obstáculos a serem superados nesse processo.

Cabem aqui reflexões a partir das questões colocadas por Varjal (2007), que condena a face seletiva da função somativa da avaliação no interior das escolas. No entanto, os documentos apontam para um acompanhamento durante o processo de formação do aluno com o intuito de reduzir o número de alunos retidos.

O PPPI também reforça a preocupação do Colégio com uma formação mais integral de seus alunos: 
Desse modo, se o foco da educação escolar visa aos princípios éticos, estéticos e epistemológicos basilares do sujeito criativo e ativo, será necessário em todos os aspectos um compromisso com o fazer e com o agir; um compromisso formativo com a cidadania aprendida numa práxis inclusiva, participativa, solidária e responsável. (UNIVERSIDADE FEDERAL DE PERNAMBUCO, 2012b, p. 18)

Nesse sentido, podemos entender que os documentos regulamentares do Colégio direcionam as práticas de avaliação da aprendizagem, e especificamente do conselho de classe, para uma perspectiva formativa, sendo este último apontado como instrumento de avaliação e reflexão coletiva. Tal reflexão envolve professores de diferentes áreas, alunos e orientadores pedagógicos que juntos nesse espaço podem trocar informações, abrindo caminho para maior interação entre os envolvidos e maior comprometimento com o processo educativo que está sendo construído no ambiente escolar.

\section{C) O FUNCIONAMENTO DO CONSELHO DE CLASSE DO CAP-UFPE: REVELANDO CONCEPÇÕES E PRÁTICAS DE AVALIAÇÃO DA APRENDIZAGEM}

Para chegarmos ao objetivo de nosso estudo, não poderíamos deixar de analisar também as concepções de avaliação que fundamentam a prática do conselho. Nesse sentido, escutamos as falas de uma amostra de professores e observamos cinco reuniões de conselho de classe promocional. ${ }^{5}$

Ao observarmos as reuniões para fins promocionais do ano letivo de 2013 , das turmas do $7^{\circ}$ ano $\mathrm{A}, 9^{\circ}$ ano $\mathrm{A}$ e $\mathrm{B}$, e $1^{\circ}$ ano do ensino médio $A$ e $B$, percebemos que a dinâmica da reunião começa com o supervisor de classe, nesse caso o coordenador do conselho, fazendo a chamada dos nomes de todos os alunos da turma a ser avaliada. Quando os nomes vão sendo chamados, os professores que sentem a necessidade de pontuar algo sobre determinado aluno se inscrevem. Terminada a chamada, o supervisor volta aos nomes destacados para começar as considerações e os encaminhamentos.

A partir disso, observamos que a maioria dos professores só fala a respeito de determinado aluno se ele for considerado
5 Em razão do calendário acadêmico e do período para a realização da pesquisa empírica, só foi possível fazer a observação nas reuniões do conselho de classe promocional. 
6 É considerado problemático o aluno que apresenta dificuldades de aprendizagem em uma ou mais disciplinas, ou que tem muitas faltas no ano letivo, falta de interesse questões de indisciplina, falta de participação "problemático", ${ }^{6}$ passível de registro para o conselho prognóstico, passível de encaminhamento ao Serviço de Orientação Educacional para comunicação com a família ou ainda passível de retenção. Dessa forma, a dinâmica das reuniões do conselho de classe demonstra ter ênfase nos alunos "problemáticos".

No entanto, a discussão sugere que, muitas vezes, a "problemática" na qual o aluno está envolvido é mais de ordem pessoal do que de aprendizagem, como justificativa para o problema:

o que eu percebo ultimamente é que os conselhos de classe a gente vem muito mais discutindo a dificuldade do menino aprender determinadas coisas mais do ponto de vista do que tá externo à escola. Que eu acho que a gente tinha que ter um jeito, que tá, o menino tem problema de saúde, ou o menino tem um problema na família... A gente teria que arranjar uma estratégia de poder aferir a aprendizagem contornando isso, do que simplesmente aceitar de porque ele tem essa dificuldade então ele tem essa avaliação. Então, às vezes a gente perde mais tempo pra discutir a vida do menino, pra justificar que ele não anda bem nos estudos, e não a gente tentar com essas dificuldades que ele enfrenta, como a gente pode trabalhar para que ele possa vencer as dificuldades mesmo nessa situação. E alguns conselhos aqui conseguem fazer isso, outros nem tanto, é uma pena, mas um dia vamos ver, né? (P6)

Em concordância com Dalben (2004, p. 27), verificamos que essa prática é comum:

Professores e alunos, em conselho de classe, tendem seriamente a explicar e justificar resultados alcançados ao longo de um tempo, muito mais do que buscar alternativas de superação.

Além disso, o trecho ressalta a preocupação do professor com a aprendizagem dos conteúdos, a qual podemos vincular a uma discussão de avaliação de mérito acadêmico, e pouca clareza em relação ao contexto social e suas repercussões na aprendizagem dos alunos.

As questões atitudinais como a não realização das tarefas, a falta de participação, os problemas de comportamento, 
as faltas frequentes, as conversas paralelas durante as aulas, a falta de interesse, a falta de compromisso, e as questões pessoais, como problemas familiares e de saúde, ganham bastante visibilidade e tempo de discussão no grupo quanto ao que deve prevalecer na hora de avaliar o aluno.

A dificuldade em ter clareza sobre quais aspectos do aluno devem ser avaliados reflete as diferentes concepções que se esbarram no espaço do conselho. Inicialmente, cada professor traz a sua avaliação com base em determinados valores e ideologias, no entanto, essas concepções precisam ser analisadas e refletidas no esforço coletivo, como afirma Pacheco (2002, p. 56):

[...] a complexidade da avaliação da aprendizagem exige um esforço conjunto de todos os atores educativos, principalmente quando se pressupõe que a escola existe para a promoção do sucesso educativo.

Por fazer parte dos contextos humanos, a avaliação é uma atividade mergulhada em ideologias e valores, estando também mergulhada em "jogos de interesses contraditórios e disputas de poder" (DIAS SOBRINHO, 2003, p. 92). Nesse sentido, as decisões que são tomadas nem sempre são aceitas por todos, podendo levar ao descrédito sobre o papel deliberativo do conselho de classe, como podemos destacar em uma das observações: "deixei de indicar há uns cinco anos, tive um aluno que faltou todas as minhas aulas, e o conselho aprovou. Não indico mais". ' Isso demonstra que as decisões coletivas não são fáceis de serem tomadas e que, por outra parte, nem sempre as funções do conselho estão claras para todos os professores, levando-os até a desacreditarem nessa instância.

Outra preocupação durante a pesquisa foi buscar apreender como as concepções de professores de diferentes áreas do conhecimento sobre a avaliação vêm fundamentando a dinâmica de funcionamento do conselho de classe do Colégio, visamos abranger diferentes concepções de avaliação considerando o referencial de formação e de experiência de cada docente entrevistado. Isso porque entendemos os professores como seres sociais, políticos e culturais, compartilhando diferentes concepções sobre a avaliação da aprendizagem. 
Embora alguns professores tragam em suas falas conceitos sobre a avaliação como medição, verificação, identificação, todos vão apresentar uma concepção aproximada de avaliação como processo, tendo no diagnóstico, no acompanhamento das aprendizagens e no confronto entre o planejamento, entre o que foi feito e o resultado conseguido, o percurso para orientar e criar novas estratégias pedagógicas: Avaliar pra mim, acho que é procurar identificar se os alunos estão ou não aprendendo. E como é que se identifica isso? Observando como é que eles estão participando das aulas, quando você faz pergunta pra ele, quando você observa como está o caderno dele, tudo isso são etapas de avaliação e quando você elabora um instrumento, um teste. Avaliar pra mim é todo momento, toda hora....... Eu faço isso quase toda hora, todo momento, eu tô sempre reavaliando, revendo, depende como o andamento da sala vai. (P3)

E como é difícil avaliar! Porque a própria avaliação é falha, é falha ou naquele dia o aluno não tá bem. Aí eu procuro fazer que eu acho que quase que uma prática daqui, fazer em momento diferente, de forma diferente, tem uma parte que é cobrada uma leitura e uma produção de texto, em outro momento é a prova tradicional, em outro momento é apresentação. Aí tudo isso vai somando pra ser a prova então de várias partes, e não uma única atividade. (P7)

Como processo, a avaliação vai apresentar algumas categorias de acordo com as compreensões dos professores entrevistados. A primeira corresponde à ideia de avaliação como um processo complexo e difícil de se realizar, pois ela não se detém a avaliar somente o mérito, mas também o valor dos processos de aprendizagem dos alunos. Dias Sobrinho (2003, p. 46) colabora com nossa reflexão sobre essa concepção apresentada pelos professores quando afirma que "a produção de juízo de valor é algo muito complexo e sobre valores não há consensos definidos”.

Avaliar as aprendizagens é lidar com a complexidade humana, dessa forma, torna-se necessário que a avaliação esteja resguardada por um sentido "ético", significando, segundo 
Hoffmann (2000), entendê-la como reflexão permanente do docente sobre sua prática pedagógica, sobre seu aluno, sobre justiça e julgamento, e sobre dignidade humana. Por não ter regras gerais, a avaliação precisa analisar todas as situações em seu contexto, nesse sentido, é preciso postura de questionamento e de discussão conjunta entre os professores (HOFFMANN, 2000). Concepções como essas estão na base dos trechos de fala acima destacados, mesmo considerando o último trecho de fala - "Aí tudo isso vai somando pra ser a prova" - revelador de que os professores ainda guardam um ranço da avaliação como medição ou como processo somativo.

Considerando ainda a complexidade da tarefa em avaliar as aprendizagens, percebemos o reconhecimento de alguns professores de que a sua avaliação individual pode ter falhas, de que é importante a observação das estratégias utilizadas pelos alunos na resolução dos problemas e a colaboração dos outros professores nos momentos de avaliação coletiva para ajudar na reflexão sobre sua prática docente:

Avaliação é muito complexo, sabe? Acho que é um dos momentos mais complicados no processo de ensino-aprendizagem é como avaliar, porque o teu instrumento é falho, tem falhas, e às vezes você não admite que ele tá com falhas. E quando você vê a resposta do menino e também serve pra isso, né? Pra gente fazer uma reflexão até dos instrumentos, tem hora que eu boto uma coisa e digo: "trivial", e eu vejo que o aluno não vai por aquele caminho que eu, na minha cabeça, eu achei que era por ali. Então até serve pra me autoavaliar e às vezes os meus colegas permitem fazer essa avaliação mais fácil do que eu ficar só no meu. (P6)

Considerar as falhas do processo avaliativo não o torna menos importante; é justamente o reconhecimento da possibilidade de cometer erros na prática avaliativa que motiva $o$ professor a estar sempre em busca de novas formas de avaliar. Acreditar que a avaliação sempre dará conta de mostrar com absoluta precisão e veracidade que o patamar de conhecimento construído é uma ilusão; mesmo utilizando técnicas e métodos considerados infalíveis, o resultado sempre será aproximado e relativo. De acordo com Dias Sobrinho (2003, p. 92), "é preciso 
afirmar que nenhuma avaliação, mesmo essa tecnicista e objetivista, jamais produz 'certezas' pois certezas não pode dar nem a mais rigorosa ciência”. Percebemos essa compreensão no trecho de fala abaixo quando diz sobre a subjetividade do resultado:

Poxa, é um tema fácil de falar, difícil de realizar! Avaliação é um processo, tá certo? Um processo de acompanhamento, sendo otimista, né? É o tempo de evolução da aprendizagem do aluno [...] se é que é possível verificar se essa evolução, se uma coisa é tão visível, que eu tenho algumas dificuldades em saber se é visível. Mas, avaliar significa acompanhar o processo para garantir, não garante nada, mas na tentativa de garantir o sucesso, por isso que a gente tá fazendo avaliação, né? Buscar informação pra orientar e reorientar algumas ações de forma que a gente consiga o sucesso, o que é difícil a gente dizer: "poxa aconteceu", acho que essas coisas em educação não são tão visíveis assim. (P4)

Nesse sentido, destacamos a importância da compreensão de que a avaliação não é um processo infalível e inquestionável, justamente por lidar com seres humanos não pode ser momentânea e categórica, ela precisa ser construída com reflexão, autoavaliação e colaboração mútua. Como podemos ver, de forma geral, os professores vão apresentar uma concepção crítica de avaliação da aprendizagem, uma concepção de avaliação como um processo permanente e contínuo de acompanhamento das aprendizagens e de possibilidades de redirecionamento da prática docente.

Essas concepções vão sendo reveladas também na dinâmica dos conselhos de classe e vão ser acrescidas de mais elementos como o que podemos destacar à frente: avaliação como processo deliberativo coletivo-reflexivo.

Em determinada reunião do conselho de classe, foi observado o esforço dos professores em refletir e decidir sobre um aluno com histórico de repetência e de problemas na aprendizagem e na família. Houve indicações para uma nova retenção, o que, nesse caso, levaria o aluno a ser excluído da escola, mas houve também o interesse e a preocupação em escutar os pares: "A produção foi muito baixa mesmo, quero ouvir o conselho" (CP1). No decorrer da discussão e diante das 
argumentações dos professores, que ora traziam as dificuldades de aprendizagem, ora traziam os problemas pessoais do aluno como explicação para esses problemas, apareceram algumas reflexões sobre o papel da escola, como:

Formalmente, quais foram as intervenções pedagógicas feitas pela escola para ajudar esse aluno? Se a familia não colabora, o que a escola faz? A escola somos nós professores e alunos, e aí, o que vamos fazer? Qual o papel da escola?. (CP2)

O debate, nesse momento, se voltou para as consequências de nova retenção na vida do aluno. Considerando os problemas familiares levantados, o conselho de classe entendeu que a retenção significava negar ao discente uma nova oportunidade para melhorar seu percurso educativo, dessa forma, deliberou-se pela promoção do aluno, assumindo então a responsabilidade e o compromisso de acompanhar mais atentamente o processo de desenvolvimento desse aluno, principalmente na relação escola-família. Dessa passagem, pode-se depreender que o coletivo buscou analisar o aluno numa dimensão integral, tentando fazer um julgamento envolvendo aspectos mais globais que uma decisão negativa (a retenção) poderia trazer para a vida do aluno. E mais: o processo decisório incluiu o compromisso coletivo com o desenvolvimento posterior do aluno.

Percebemos, nesse sentido, a importância que o conselho de classe assume como espaço fundamental de reflexão coletiva sobre o papel da escola e da avaliação na vida do aluno, como também percebemos a importância de buscar compreender o aluno como um ser formado por diferentes dimensões, as quais não podem ser tomadas isoladamente, mas em conjunto na constituição do significado do ser humano. Pode-se perceber por essa passagem que a avaliação coletiva vai exercer o seu papel de questionar as práticas cotidianas da escola, de questionar as decisões tomadas (ou não tomadas) para reverter a situação do aluno.

Reconhecendo a importância desse espaço reflexivo e os efeitos da avaliação sobre o aluno, destacamos a postura de compromisso e a responsabilidade assumida no conselho de classe: 
[...] então eu interfiro muito e levo bastantes elementos pra gente pensar, acho que eu contribuo, não sei se positivamente (risos), mas contribuo um bocado. Algumas pessoas acham que a gente fala demais, mas é necessário, justamente no momento de avaliação final que é aquele que dá o caminho, né? Se o menino vai prosseguir com os estudos ou não, isso pra mim é um dos piores. Esses momentos, pra gente tomar uma decisão dessa tem que ser bastante consciente, pé no chão, com todos os elementos porque pra eles é uma, é a vida, né? Para as famílias também, a pressão é grande [...]. (P6)

Dias Sobrinho (2003, p. 92) revela: "nenhuma avaliação jamais é neutra ou inócua”. Ao optarmos por utilizar uma determinada avaliação em detrimento de outra, estamos consequentemente optando pelos efeitos que iremos produzir; desse modo, a deliberação de um conselho de classe não pode estar embasada em opiniões e interesses pessoais ou de grupo, é preciso o exercício de muita reflexão sobre o que se tem feito e o que ainda se pode fazer, isso demanda compromisso e colaboração. O professor sozinho possivelmente não conseguirá observar e apreender o aluno como um todo. Uma instância colegiada de avaliação permite que isso aconteça no momento em que todos os professores apresentam suas observações, dúvidas e queixas diante do grande grupo e todos colaboram com a avaliação tendo como foco um objetivo comum: melhorar o andamento das aprendizagens dos alunos.

Foi observada também em algumas reuniões do conselho de classe a preocupação de alguns professores em pontuar positivamente os alunos que superaram dificuldades no decorrer do ano letivo, considerando os avanços realizados por eles, como comprova esta fala:

[...] eu não vou pro conselho já com nomes pra indicar pra retenção não. Eu faço elogios aos alunos, fiz elogios inclusive esse semestre, esse final de ano, eu elogiei alunos que tiveram grandes dificuldades. Por quê? Porque eu elogiei o esforço que eles fizeram para não ficar, para melhorar com relação ao anterior, eu não elogio aluno que tira dez não, eu elogio aluno que se esforça, tá entendendo? (P5) 
Tal postura se aproxima de uma concepção formativa de avaliação, tal como Hoffmann (2009, p. 20) nos ajuda a entender que

[...] avaliação não deve ficar presa ao passado, reunindo informações para explicar uma etapa de aprendizagem, mas acompanhar de perto com atenção e seriedade todas as etapas do aluno para ajudá-lo no seu desenvolvimento.

E ainda: "Cada manifestação do aluno é um indício de continuidade, por onde o professor deve prosseguir" (HOFFMANN, 2009, p. 21).

Embora a reunião do conselho de classe apresente com mais frequência discussões sobre os aspectos problemáticos dos alunos, percebe-se o aparecimento de elogios, como forma de ampliar a visão de outro professor para aspectos mais qualitativos, desse modo, opiniões, posições e decisões individuais passam a ser refletidas, transformadas e decididas por todos, tomando como base os avanços percorridos pelos alunos. Decisões construídas na inter-relação das diferentes disciplinas em torno do mesmo objetivo que é o desenvolvimento do aluno:

[...] então é bom porque você tem uma visão geral da situação do aluno nas outras disciplinas. Além de ter esse caráter democrático, de todo professor poder dar a sua opinião sobre cada um daquele aluno e inclusive aluno que vai pra o conselho "- esse vai ser reprovado porque ele tá péssimo na minha disciplina”, mas, lá na discussão, cada professor levanta observações que você não vê, é como se você não avaliasse sozinho, os outros professores estão the ajudando a avaliar. [...] já teve aqui o aluno que tirou nota baixa na disciplina de exatas e o professor tinha dado como, o indicou para reprovação no conselho, mas, esse mesmo aluno tinha participado de uma olimpíada daquela mesma disciplina e ganhou medalha. Então, ele não pode ser considerado que é ruim naquela disciplina, mas naquele momento da prova, ele foi mal e aí o conselho entendeu que não era o suficiente pra reprovar. (P7)

Compreendemos então a importância do conselho de classe na tarefa de avaliar o aluno. Esse espaço coletivo 
mostra-se determinante para que as várias dimensões dos alunos sejam conhecidas e reconhecidas pelos professores. Dalben (2004) ajuda em nossa reflexão quando aponta para a necessidade de conhecer o aluno em todas as suas dimensões, em seus valores socioculturais e em suas necessidades de conhecimento tornando-o foco de todo o trabalho de investigação.

Nesse sentido, as reflexões e discussões coletivas com foco na avaliação dos alunos também trazem a possibilidade de mudança, tanto da prática quanto da concepção. Um professor com suas preconcepções sobre determinado aluno, por exemplo, tem a oportunidade de escutar os colegas, ampliar sua visão do aluno e reconstruir sua prática, realizando então uma avaliação mais justa a partir de uma mudança de concepção sobre o que é avaliar, pois

[...] a transformação da prática pedagógica liga-se estreitamente à alteração da concepção de avaliação porque a construção do processo avaliativo expressa o conhecimento da e sobre a escola que é produzido na própria relação de avaliação. (DALBEN, 2004, p. 70)

Nesse caminho, uma terceira concepção vai emergir: avaliação é um processo de mudança da prática docente. Ou seja, a avaliação da aprendizagem não só diz respeito ao aluno, mas também aos próprios professores:

[...] eu chego lá com a minha leitura, a minha visão, as minhas limitações, numa compreensão de uma realidade, no caso de aluno, né? E quando eu chego lá, eu escuto as pessoas, eu paro para pensar, reflito e certamente quando eu volto pra minha sala de aula eu não sou mais a mesma pessoa em relação ao grupo, então claro que mexe com a minha avaliação. (P4)

[...] então, é esse momento do conselho que você tem que usar da balança, da sensatez, do equilíbrio. E aí quando a gente volta, a gente volta com atitudes diferentes, pedagógicas, mesmo humanas, do relacionamento, tá certo? Às vezes a gente ouve uma história que é tão pesada e a gente volta diferente, talvez exigindo menos do aluno ou com mais compreensão pelo menos, entende? Então realmente o conselho de classe quando ele é muito sério, 
quando ele é feito com as prerrogativas de um conselho, ele modifica todo o mundo, porque é uma questão de relação que se dá ali e a gente vai construir outro fazer, com certeza. (P8)

Nessa compreensão são importantes a atenção dos percursos da aprendizagem dos alunos e o seu acompanhamento, bem como reflexão e flexibilidade para redirecionar a prática, como também estabelecer o diálogo, que segundo Hadji (apud LUIS, 2010, p. 43) “uma avaliação só será verdadeiramente formativa se houver uma comunicação útil, um esforço para compreender melhor como as coisas se passam". Nesse sentido, nos parece que o conselho de classe vem exercendo essa função comunicativa entre os professores e contribuindo, de alguma forma, para o docente revisitar suas práticas.

Outro ponto relevante que fez parte da nossa análise referiu-se à participação dos alunos no conselho de classe. Os professores entrevistados deram destaque para essa participação. Alguns a classificaram como definidora, construtiva, enriquecedora e importante, mas principalmente como processo de avaliação mútua, pela troca possível entre professor e aluno no momento da avaliação.

A participação dos alunos proporciona o diálogo e favorece a aprendizagem à medida que os alunos conseguem espaço para apresentar suas queixas e observações sobre dificuldades no processo ensino-aprendizagem e na relação interpessoal professor-aluno, e também à medida que o professor reflete e elabora novas estratégias pedagógicas a partir dessas considerações:

Primeiramente é um momento que ele também nos avalia, então, a gente sempre avalia o aluno, mas não sabe como é que tá nossa disciplina. Então nesse momento, que o conselho tem a participação do aluno, é que vem o feedback e aí a gente corrige também. [...] Os alunos colaboram muito com isso na participação deles, eles fazem observações que a gente enquanto professor não tinha atentado para aquilo: “- 0 professor tá trabalhando muito uma metodologia interessante, mas tornou-se cansativa porque a aula ficou repetitiva". Aí você já se toca pra modificar alguma coisa. (P6) 
Acho que favorece na hora da troca, é o momento que os alunos estão ali presentes podendo se colocar de uma certa forma menos formal ou individual com único professor, porque a sala de aula é um pouco assim, né? É a sala com a professora X, com a professora $Y$, ali tá todos os alunos com todos os professores. Então às vezes o próprio aluno diz uma fala que um professor corrobora com isso também e o outro que não vê passa a indagar que de repente isso pode acontecer de fato, então acho que isso é um momento único, acho que é um momento muito importante por sinal, então, acredito até que é um momento, um dos mais importantes momentos. (P9)

Embora todos afirmem a importância da participação dos alunos, nem sempre ela aparece nos resultados esperados; alguns professores esclarecem que para alcançar os objetivos específicos das disciplinas nem sempre podem modificar a metodologia, outros deixam claro que as mudanças nem sempre acontecem de imediato, outros ainda afirmam depender do professor a decisão de mudar ou não, a partir da pertinência da solicitação ou reclamação feita pelos estudantes:

Acho que a participação do aluno sempre favorece, não sei se a avaliação da aprendizagem, favorece a gente saber um pouco o que os alunos pensam das aulas da gente, pra gente refletir sobre o que a gente tá fazendo e redirecionar se achar que é pertinente. (P3)

De todo modo, foi possível apreender um movimento a partir do que foi tratado no conselho de classe; a participação dos alunos sempre mexe com o professor:

Eu acho que favorece, embora alguns alunos digam assim: "-Ah, mas a gente vai pro conselho e não consegue mudar a forma do professor". Mas claro, tem algumas pessoas que são mais inflexíveis em algumas posições, mas assim, só o ouvir, o escutar, o expor publicamente a situação eu acho que já ajuda muito. Até quando eles colocam assim: "- Não, a prova foi muito difícil, tal atividade, o professor passou um seminário muito longo, exigiu muito", eles conseguem expor isso. Então só o fato de colocar, mesmo que o professor não mude assim em algumas posições, assim, quando ele volta pra sala ele conversa, ele sempre conversa, 
ele sempre volta e diz: "- Não, mas vocês falaram no conselho, mas eu coloquei que era dessa forma". Ele sempre retoma, então eu acho que o conselho ajuda, sempre ajuda na avaliação. (P2)

Nessa dinâmica percebem-se alguns princípios da avaliação como negociação, apontados por Fernandes (2005), correspondentes à necessidade de os professores partilharem o poder de avaliar com os alunos, o feedback nas suas variadas formas, a avaliação servindo mais para ajudar nas aprendizagens do que para classificar, o privilégio da avaliação formativa, entre outros.

Isso revela o quanto a participação dos alunos no conselho de classe é fundamental para o processo de avaliação da aprendizagem tanto em relação ao diálogo, quanto a uma formação mais completa no sentido de que eles se tornam coautores da sua própria avaliação, colocando suas reivindicações, opiniões e sugestões, mas também assumindo compromisso diante do que está sendo negociado.

\section{CONSIDERAÇÕES FINAIS}

Este estudo foi realizado em resposta ao nosso questionamento inicial de entender se o conselho de classe poderia atuar também dentro de uma perspectiva de avaliação formativa, não se restringindo ao movimento deliberativo de retenção ou promoção do estudante. Procuramos as respostas em uma situação pedagógica específica: a prática realizada num Colégio de Aplicação. Esse campo empírico pode limitar nossos achados especificamente a este estudo de caso, dada sua especificidade.

Consideramos que foi possível perceber na experiência analisada elementos que apontam para uma dinâmica e compreensão de avaliação da aprendizagem como processo. As observações realizadas, as entrevistas e as análises dos documentos revelaram um trabalho coletivo e constante de reflexão sobre o planejado, o feito, o alcançado e o que ainda falta fazer, possibilitando, então, a criação e a reformulação de estratégias pedagógicas que tenham por função desenvolver e melhorar o processo ensino-aprendizagem. 
Encontramos o esforço de construção de um espaço coletivo de avaliação que proporciona reflexões sobre a avaliação concebida teoricamente e a avaliação realizada em sala de aula. O diálogo estabelecido nas inter-relações entre professores-alunos-professores no conselho de classe do CAp-UFPE demonstra que, embora existam dificuldades, é possível construir uma instância avaliativa colegiada que tenha vocação para se transformar num instrumento de avaliação capaz de subsidiar o processo formativo de seus alunos.

Por outra parte, alguns limites também foram encontrados como, por exemplo: a ausência de alunos na reunião do conselho promocional; a falta de ações para uma avaliação de grupos ou turmas; foco no desempenho individual dos alunos. Esses são elementos que merecem reflexão do ponto de vista das concepções sobre avaliação formativa e sobre sua prática, redundando na necessidade de continuar estudando sobre a temática.

Assim, é importante analisar as contribuições que esta pesquisa pode oferecer ao estudo da relação entre a avaliação da aprendizagem e o conselho de classe, favorecendo a reflexão, a discussão e o incentivo para futuras pesquisas na área, a fim de ampliar e aprofundar o debate e a construção de práticas avaliativas que alcancem uma dimensão mais humana.

\section{REFERÊNCIAS}

BRASIL. Ministério da Educação. Lei n. 9.394 de 20 de dezembro de 1996. Estabelece as Diretrizes e Bases da Educação Nacional. Brasília, DF: MEC, 1996.

DALBEN, Ângela Imaculada Loureiro de Freitas. Conselhos de Classe e Avaliação: perspectivas na gestão pedagógica da escola. Campinas: Papirus, 2004.

DIAS SOBRINHO, José. Avaliação: políticas educacionais e reformas da educação superior. São Paulo: Cortez, 2003.

FERNANDES, Domingos. Dos fundamentos e das práticas. Da avaliação como medida à avaliação formativa (AFA). In: __ . Avaliação das aprendizagens: desafios às teorias, práticas e políticas. Lisboa: Texto, 2005. p. 55-63.

FREIRE, Paulo. Pedagogia do oprimido. 32. ed. Rio de Janeiro: Paz e Terra, 2002.

GIL, Antonio Carlos. Como elaborar projetos de pesquisa. 4. ed. São Paulo:

Atlas, 2006. 
GUERRA, Mônica Galante. Conselho de classe: que espaço é esse? 2006.

Dissertação (Mestrado em Linguística Aplicada e Estudos da Linguagem) Pontifícia Universidade Católica de São Paulo, São Paulo, 2006.

HOFFMANN, Jussara. Avaliação - mito \& desafio: uma perspectiva construtivista. 29. ed. Porto Alegre: Mediação, 2000.

2009.

Avaliar para promover: as setas do caminho. Porto Alegre: Mediação,

LIBÂNEO, José Carlos. Didática. São Paulo: Cortez, 1994.

LUCKESI, Cipriano Carlos. Avaliação da aprendizagem escolar: estudos e proposições. 18. ed. São Paulo: Cortez, 2006.

LUIS, Suzana Maria Barrios. De que avaliação precisamos em arte e educação física? In: SILVA, Janssen Felipe da Silva; HOFFMANN, Jussara; ESTEBAN, Maria Teresa (Org.). Práticas avaliativas e aprendizagens significativas. Porto Alegre: Mediação, 2010.

MATTOS, Carmen Lúcia Guimarães de Mattos. O conselho de classe e a construção do fracasso Escolar. Educação e Pesquisa, São Paulo, v. 31, n. 2, p. 215-228, maio/ago. 2005.

MINAYO, Maria Cecília S. O desafio do conhecimento. São Paulo: Hucitec, 2010.

PACHECO, José Augusto. Critérios de avaliação na escola. In:

Avaliação das aprendizagens: das concepções às práticas. Lisboa: Departamento da Educação Básica, 2002. p. 53-64.

PEREIRA, Gilson de Almeida. Conselho de classe: A cultura do faz-de-conta ou a possibilidade de um novo Ethos Educacional? Ciências e Letras, Porto Alegre, v. 36, p. 187-196, 2004.

RICHARDSON, Roberto Jarry. Métodos quantitativos e qualitativos. In: RICHARDSON, Roberto Jarry et al. Pesquisa Social: métodos e técnicas. São Paulo: Atlas, 1999.

SANT'ANNA, Ilza Martins. Por que avaliar? Como avaliar? Critérios e instrumentos. 14. ed. Petrópolis, RJ: Vozes, 2010.

SCRIVEN, Michael. The methodology of evaluation. Chicago IL: Rand McNally, 1967. (Aera Monograph series on curriculum evaluation, n. 1).

SIMÕES, Gonçalo Augusto Gomes. A avaliação do desempenho docente. Contributos para uma análise crítica. Lisboa: Texto Editora, 2000.

UNIVERSIDADE FEDERAL DE PERNAMBUCO. Colégio de Aplicação. Instrução Normativa n. 01/93. Recife: UFPE/CAp, 1993.

. Instrução n. 01/99. B.0. UFPE, Recife, v. 34, n. 85, p. 01-04, 28 dez. 1999, Número especial.

Orientações Pedagógicas Iniciais. Serviço de Orientação Educacional e Pedagógica. Recife: CAp/UFPE, 2012a.

Projeto Político Pedagógico Institucionalizado. Recife: CAp/UFPE, 2012b. 
VARJAL, Elizabeth. Avaliação das aprendizagens na escola inclusiva. In: CONFERÊNCIA MUNICIPAL DE EDUCAÇÃO DE MORENO, 1., 2007, Moreno, PE. Palestra... Moreno, PE, 2007.

ZABALA, Antoni. A prática educativa: como ensinar. Porto Alegre: Artmed, 1998.

\section{RUBIA CAVALCANTE VICENTE MAGNATA}

Mestranda do Programa Associado de Pós-Graduação em Educação, Culturas e Identidades da Fundação Joaquim Nabuco e da Universidade Federal Rural de Pernambuco (UFRPE), Recife, Pernambuco, Brasil rubia.cv@hotmail.com

\section{ANA LÚCIA FELIX DOS SANTOS}

Professora Doutora do Centro de Educação e do Programa de Pós-Graduação em Educação da Universidade Federal de Pernambuco (UFPE), Recife, Pernambuco, Brasil analufelix@gmail.com 
